\title{
PADRÕES DE ASSENTAMENTO E FORMAÇÃO DE SAMBAQUIS EM SANTA CATARINA
}

Este projeto ocupa-se do estudo de um conjunto de sambaquis instalado em uma área do litoral meridional do estado de Santa Catarina, tendo seu epicentro na Lagoa do Camacho, daí seu nome em inglês (Camacho Archaeological Project - CAP). Elaborado originalmente por seus atuais coordenadores: Dr. Paulo De Blasis (Museu de Arqueologia e Etnologia da Univ. de S. Paulo, MAE-USP), Dra. Maria Dulce Gaspar (Museu Nacional, Univ. Fed. do Rio de Janeiro-UFRJ e os Drs. Paul Fish \& Suzanne Fish (do Arizona State Museum, University of Arizona), o projeto resulta também da convergência de interesses de investigação de outros pesquisadores de diferentes especialidades e instituições brasileiras e norte-americanas, os Drs. Marisa Afonso e Levy Figuti (MAE-USP), Marta Lahr e Sabine Eggers (IB-USP), e ainda Peter Pilles, do Coconino National Forest Park, Arizona. Estes pesquisadores buscam, através da integração de perspectivas metodológicas diversas como a zooarqueologia, a paleodemografia e a paleopatologia, a análise dos padrões de assentamento, a geoarqueologia e o estudo da organização do espaço interno dos sítios, uma visão ampla dos grupos humanos que ergueram estas estruturas tão impressionantes, suas características biológicas, demográficas, tecnológicas e econômicas, assim como de organização social.

A área de atuação do projeto situa-se no litoral sul de Santa Catarina, configurada pela Lagoa do Camacho e seu entorno, abrangendo os municípios de Laguna, Tubarão e Jaguaruna. Trata-se de uma área que abrange um número significativo de sítios arqueológicos instalados em diferentes contextos micro-ambientais envolvendo a linha de praia, as lagoas do Camacho, da Encantada e de Jaguaruna, as paleodunas e serras isoladas, conectando-se com as escarpas do planalto.

Os objetivos do projeto partem de duas perspectivas teóricas básicas. De um lado, uma abordagem sistêmica de um conjunto de sambaquis em seu contexto ambiental, seu território, perspectiva esta ainda ausente nos estudos com sítios litorâneos no Brasil. A principal hipótese de trabalho que fundamenta esta perspectiva é a de que os sambaquis desta região, particularmente os maiores, representam um processo de sedentarização, adensamento demográfico e complexificação na organização social de uma população de pescadores-coletores-caçadores que parece tomar forma a partir de 3.000 anos atrás aproximadamente.

De outro lado, este projeto explora o conceito de sambaqui enquanto estrutura intencionalmente construída, rejeitando a idéia predominante de que estes sítios são, simplesmente, resultado do descarte dos subprodutos das atividades de subsistência das populações sambaquieiras (para uma discussão deste aspecto ver Gaspar \& De Blasis 1992). Este enfoque decorre do fato de que, apesar de pesquisados desde o século passado e, de uma maneira metodologicamente mais sistemática desde os anos 50 , os processos de formação destes sítios permanecem muito mal compreendidos. A análise crítica da bibliografia disponível, de caráter predominantemente arqueográfico, mostra modelos interpretativos bastante simplistas, onde predomina a perspectiva de que os sambaquis são produto de "grupos de coletores de moluscos que evoluíram para pescadores", "bandos com grande mobilidade", etc.. Os estudos até o momento falharam em reconhecer que estes sítios, caracterizados por estruturas complexas e representando padrões de ocupação e de comportamento reiterados ao longo do tempo, são produto intencional de sociedades demograficamente expressivas e com padrões de organização social bem mais complexos do que se tem aventado até o presente (para uma discussão mais ampla destes problemas na região ver De Blasis et alii, no prelo).

Tendo em vista que a área de pesquisa é ocupada por populações de pescadores e coletores de moluscos e camarões que guardam ainda estilos de vida e subsistência bastante tradicionais, mais um objetivo foi considerado, qual seja, investigar, em uma perspectiva etnoarqueológica, as características ambientais, tecnológicas e de organização social que estruturam uma economia que, baseada nos recursos locais e regionais, possa fornecer parâmetros de comparação para a formulação de um modelo econômico que teria sustentado o adensa- 
mento demográfico expressivo que se supõe tenha ocorrido ao longo de mais de 4.000 anos de evolução das sociedades sambaquieiras. Por fim, mas não menos importante, o projeto tem ainda em vista, em parceria com a $11^{\mathrm{a}}$. CR/IPHAN de Santa Catarina, emular, sobretudo em âmbito local, medidas básicas de preservação dos sambaquis enquanto patrimônio cultural e ambiental.

O projeto teve uma primeira campanha de campo no inverno de 1997 com uma grande equipe de diferentes nacionalidades, contando com o apoio de agências de fomento à pesquisa brasileiras e norte-americanas. ${ }^{1}$ A etapa de campo, de 40 dias de duração, envolveu uma variedade de atividades, sendo a mais importante a preparação e registro de cerca de 125 metros lineares de perfis estratigráficos na porção central do sambaqui Jaboticabeira II, acompanhados de uma série de cortes estratigráficos (pequenas trincheiras) abertos em sua periferia, com coletas de amostras para datação radiocarbônica e para as análises zooarqueológicas. ${ }^{2}$ Além disso, foram registrados pequenos perfis nos sambaquis de Garopaba do Sul, Mato Alto, Encantada II, Figueirinha e Morrote, sendo que neste último foi também realizada uma coleta sistemática de superfície. Por fim, foram realizadas observações etno-arqueológicas preliminares junto à comunidade local da vila de Garopaba do Sul, e ainda algumas palestras de divulgação do projeto em Jaguaruna e Laguna.

O levantamento de sítios no espaço regional, sobretudo na faixa costeira, mostra sambaquis de tamanho e estrutura diversificadas, com diferentes padrões de acumulação, onde unidades maiores e menores parecem configurar pequenos conjuntos

(1) Agradecemos o inestimável apoio das seguintes instituições: Wenner-Gren Foundation, Fundação de Amparo à Pesquisa do Estado de São Paulo (FAPESP), Heinz Foundation, Pró-Reitoria de Pesquisa da Universidade de S. Paulo, Universidade Federal do Rio de Janeiro-UFRJ e o Instituto do Patrimônio Histórico e Artístico Nacional (IPHAN/ $11^{\mathrm{a}}$.CR), que tornaram este projeto uma realidade.

(2) A apresentação de trabalhos com os resultados preliminares do projeto foi feita em dois eventos científicos, a XI Reunião Científica da Sociedade de Arqueologia Brasileira (SAB) no Rio de Janeiro, setembro de 1997, e o $63^{\text {rd }}$ Annual Meeting of the Society for American Archaeology (SAA) em Seattle, abril de 1998, além dos relatórios encaminhados às agências financiadoras acima listadas. Uma discussão mais ampla dos resultados preliminares pode ser encontrada em Fish et alii, no prelo. concêntricos dispersos pela região. Estes elementos apontam para a presença de sistemas articulados de assentamento com diferenças funcionais consideráveis entre seus componentes. $\mathrm{O}$ trabalho de investigação intra-sítio foi iniciado sobretudo em Jaboticabeira II, com a abertura de extensos perfis e trincheiras. Neste sambaqui de médio porte foi iniciado o estudo dos processos de formação que determinaram sua construção, envolvendo não só análises crono-estratigráficas e demográficas mas também uma investigação zooarqueológica sistemática das camadas que o compõem. ${ }^{3}$

Uma sequência de dezoito datações radiocarbônicas, coletadas em diferentes locais do sítio, mostram grande consistência interna e indicam que toda a estrutura do sambaqui foi construída em cerca de 1.000 anos, entre 2.880 e 1.805 anos BP. Isto, associado às evidências de um grande número de sepultamentos presentes no sítio, reforça a noção de uma expressiva densidade demográfica nesta região lagunar durante o período (ver Fish et alii, op. cit., para alguns parâmetros quantitativos e uma discussão desta questão). De fato, apenas na abertura dos perfis, sem escavações horizontais mais amplas, foram registrados 52 sepultamentos (muitos dos quais secundários ou alterados durante a própria história de construção do sambaqui), dispersos por praticamente todo o sítio. Estes sepultamentos são, em sua maior parte, marcados por grande parafernália ritual (fogueiras, seixos e artefatos associados, grande número de buracos de estaca, cobertura com amontoados de conchas), o que os torna uma referência fundamental para o próprio processo de construção do sítio.

Além disso, duas datações da camada escura superior que também se encontra no sambaqui do Morrote (2.075 e $1.975 \mathrm{BP}$ ) mostram que as camadas superiores de ambos os sítios são contemporâneas, integrando um horizonte de ocupação mais amplo, confirmando, portanto, a idéia de um sistema de assentamento regional. Uma última datação, proveniente do topo do grande sambaqui de Garopaba do Sul (2.840 BP), indica que aquele sítio tinha já as enormes dimensões que exibe hoje na época em que Jaboticabeira II começava a ser erigido, confirmando as expectativas de diacronia em

(3) Os estudos zooarqueológicos no sambaqui Joboticabeira II são o tema do trabalho de Mestrado de Daniela M. Klökler, sob orientação do Dr. Levy Figuti, sob os auspícios da FAPESP. 
relação aos assentamentos da região (como se sabe, este enorme sambaqui, hoje com cerca de 22 metros de altura, era bem maior, tendo sido explorado intensivamente para a extração de conchas durante as últimas décadas. Assim, sua ocupação certamente prosseguiu durante a fase de construção de Jaboticabeira II).

A coleção proveniente da coleta sistemática de superfície no sambaqui do Morrote (sobretudo da camada escura superior, datada por volta de 2.000 anos atrás), com pouco mais de um milhar de artefatos líticos, encontra-se em estudo, e vai se constituir em uma importante coleção de referência sobre atividades cotidianas dos sambaquieiros, devido à ausência recorrente, até o momento, de artefatos de outra natureza. As referências disponíveis na bibliografia acerca dos remanescentes líticos dos sambaquis são pobres e pouco sistemáti- cas, e a análise em andamento busca explorar alguns padrões tecno-morfológicos dos artefatos, pistas para suas características funcionais.

De fato, esta indústria, recorrente em ambos os sítios trabalhados, reforça a idéia, cada vez menos improvável, de que a camada escura, rica em vestígios orgânicos e restos de peixe, que recobre a maior parte dos sambaquis da região, esteja associada a uma tecnologia de manejo ou cultivo incipiente (garden agriculture) de recursos vegetais, hipótese esta aliás já aventada para o litoral do Rio de Janeiro (Tenório 1991). Vem ainda em apoio a esta idéia o horizonte cronológico relativamente tardio (como vimos, por volta de $2.000 \mathrm{BP}$ ) destas camadas superiores de ocupação dos sambaquis, e sua associação com vestígios cerâmicos, às vezes em quantidade significativa, documentada em alguns destes sítios litorâneos (p.e. Beck 1968, Bryan 1993).

\section{Referências bibliográficas}

BECK, A.

1968 A cerâmica dos sambaquis do litoral norte de Santa Catarina. Pesquisas (Antropologia) 18: 89-100.

BRYAN, A.L.

1993 The Sambaqui at Forte Marechal Luz, State of Santa Catarina, Brazil. A. L. Bryan; R. Gruhun (Eds.) Brazilian Studies. Corvallis, Center for the Study of the First Americans, Oregon St. University.

De BLASIS, P.; SUZANNE K.F.; GASPAR, M.D.; FISH, P.R. Some references for the discussion of complexity among the sambaqui mound-builders from the southern shores of Brasil. Revista de Arqueologia Americana, México (no prelo).

FISH, S.K.; De BLASIS, P.; GASPAR, M.D.; FISH, P.R.

Incremental events in the construction of sambaquis, southeastern Santa Catarina. Anais da VIII Reunião Científica da Sociedade de Arqueologia Brasileira (SAB), Rio de Janeiro (no prelo).

Recebido para publicação em 10 de setembro de 1998.
GASPAR, M.D.; De BLASIS, P.

1992 Construção de sambaquis. Anais da VI Reunião Científica da Sociedade de Arqueologia Brasileira, 2: 811-820, Rio de Janeiro.

TENÓRIO, M.C.

1991 A importância da coleta de vegetais no advento da agricultura. Dissertação de Mestrado, Universidade Federal do Rio de Janeiro.

Paulo De Blasis* Marisa Coutinho Afonso* Levy Figuti* Paul Fish** Suzanne Fish ${ }^{* *}$ Maria Dulce Gaspar*** Sabine Eggers**** Marta Mirazón Lahr****

(*)Museu de Arqueologia e Etnologia da Universidade de São Paulo (MAE-USP).

(**) Arizona State Museum, University of Arizona.

(***) Museu Nacional da Universidade Federal do Rio de Janeiro/CNPq.

(****) Instituto de Biociências da Universidade de São Paulo (IB-USP). 